\title{
Virtual Reality Glasses and "Eye-Hands Blind Technique" for Microsurgical Training in Neurosurgery
}

\section{Choque-Velasquez, Joham}

2018-04

Choque-Velasquez , J , Colasanti , R , Collan , J , Kinnunen , R , Jahromi , B R \& Hernesniemi , J 2018 , ' Virtual Reality Glasses and "Eye-Hands Blind Technique" for

Microsurgical Training in Neurosurgery ' , World Neurosurgery , vol. 112 , pp. 126-130 . https://doi.org/10.1016/j.wne

http://hdl.handle.net/10138/302412

https://doi.org/10.1016/j.wneu.2018.01.067

publishedVersion

Downloaded from Helda, University of Helsinki institutional repository.

This is an electronic reprint of the original article.

This reprint may differ from the original in pagination and typographic detail.

Please cite the original version. 


\title{
Virtual Reality Glasses and "Eye-Hands Blind Technique" for Microsurgical Training in Neurosurgery
}

\author{
Joham Choque-Velasquez ${ }^{1}$, Roberto Colasanti ${ }^{1-3}$, Juhani Collan $^{4}$, Riina Kinnunen ${ }^{5}$, Behnam Rezai Jahromi ${ }^{1}$, \\ Juha Hernesniemi ${ }^{1}$
}

OBJECTIVE: Microsurgical skills and eye-hand coordination need continuous training to be developed and refined. However, well-equipped microsurgical laboratories are not so widespread as their setup is expensive. Herein, we present a novel microsurgical training system that requires a high-resolution personal computer screen, smartphones, and virtual reality glasses.

METHODS: A smartphone placed on a holder at a height of about $15-20 \mathrm{~cm}$ from the surgical target field is used as the webcam of the computer. A specific software is used to duplicate the video camera image. The video may be transferred from the computer to another smartphone, which may be connected to virtual reality glasses.

RESULTS: Using the previously described training model, we progressively performed more and more complex microsurgical exercises. It did not take long to set up our system, thus saving time for the training sessions.

CONCLUSION: Our proposed training model may represent an affordable and efficient system to improve eyehand coordination and dexterity in using not only the operating microscope but also endoscopes and exoscopes.

\footnotetext{
Key words

Exoscope

- Eye-hands blind technique

- Microsurgery

- Microsurgical training

- Neuroendoscopy

- Smartphone

Virtual reality glasses
}

Abbreviations and Acronyms

EHB: Eye-hands blind

VR: Virtual reality

From the ${ }^{1}$ Department of Neurosurgery, Helsinki University Central Hospital, Helsinki, Finland; ${ }^{2}$ Department of Neurosurgery, Umberto I General Hospital, Università Politecnica

\section{INTRODUCTION}

echnologic advances have driven the development of modern neurosurgery. The introduction of the surgical microscope resulted in a marked improvement in postoperative results. New complementary devices, such as endoscopes and lastly exoscopes, have been introduced in the past decades and are incessantly refined. ${ }^{\mathrm{I}-6}$

Residents and young surgeons require a continuous training process in order to develop eye-hand coordination and dexterity in using these tools. ${ }^{7}$ Well-equipped microsurgical laboratories are available only in advanced countries. As a consequence, most residents and surgeons have no access to those. In addition, microsurgical tools are expensive, and it is not so easy to set up an affordable self-laboratory.

In this regard, modern technology may be useful to develop new and less expensive devices for microsurgical training. Herein, we present a novel microsurgical training system that does not require a conventional microscope, an endoscope, or an exosocope. On the other hand, our training model is based on the "eye-hands blind (EHB) technique" and requires a high-resolution personal computer screen, smartphones, and virtual reality (VR) glasses.

\section{METHODS}

Our training model requires the following tools:

- a Mac running OS X Yosemite or later versions (Apple Inc., Cupertino, California, USA) with a high-resolution screen and delle Marche, Ancona; ${ }^{3}$ Department of Neurosurgery, Ospedali Riuniti Marche Nord, Pesaro, Italy; ${ }^{4}$ Department of Oncology, Helsinki University Hospital, Helsinki; and ${ }^{\mathbf{5}}$ School of Business and Management, Lappeenranta University of Technology, Lappeenranta, Finland

To whom correspondence should be addressed: Joham Choque-Velasquez, M.D. [E-mail: johchove@hotmail.com]

$\nabla$ Supplementary digital content available online.

Citation: World Neurosurg. (2018) 112:126-130 https://doi.org/10.1016/j.wneu.2018.01.067

Journal homepage: www.WORLDNEUROSURGERY.org

Available online: www.sciencedirect.com

1878-8750/\$ - see front matter (c) 2018 Elsevier Inc. All rights reserved. 
free software packages (QuickTime Player, TeamViewer, and Reality Augmented);

- 2 iPhones (Apple Inc., Cupertino, California, USA) with a highresolution video camera (the software should be updated to the last iOX version, and TeamViewer installed);

- VR glasses;

an IOS lightning cable (Apple Inc., Cupertino, California, USA); and

- conventional microinstruments.

Table 1 compares the costs of the traditional training systems to those of our training model.

Next, the following steps are required (Figures 1 and 2):

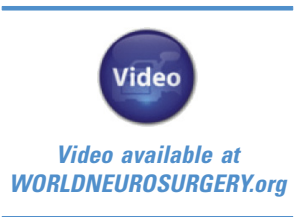

. The video may be transferred from the computer to another iPhone by using TeamViewer. This second iPhone may be connected to VR glasses (VR glasses and EHB-VR-EHBtechnique).

\section{RESULTS}

At the beginning, using the previously described training model, we practiced easy tasks with microscissors and microforceps, in order to get the feel with the almost inexistent tridimensional image (Video 1, illustrating our microsurgical training looking at the computer screen). Then, once we improved our EHB technique, we progressively performed more complex exercises such as microsutures with 7 -o and Io-o polypropylene, as well as microanastomosis. It did not take long to set up our system, thus saving time for the training sessions.

By using VR glasses, we were able to perform an EHB procedure (Video 2, illustrating our microsurgical training using VR glasses).

From the analysis of the recorded training sessions of a neurosurgeon with 3 years of experience, we noted an improvement of the average time to perform 5 consecutive sutures between the initial baseline training set and the 3-months' training sessions, as well as between the 3 -month and 5 -month training sessions. A statistically significant improvement was observed using both the computer screen and VR glasses (Table 2).

3. A recording window will appear on the screen. The iPhone video camera is used as the webcam of the computer.

4. The iPhone is placed on a holder at a height of about $15-20 \mathrm{~cm}$ from the surgical target field in order to have an adequate working distance (for the initial tasks we used an inverted glass).

5. At this point, it is possible to start the training looking at the computer screen, with the so-called Computer Screen and EHB technique.

Table 1. Comparison of Costs of Traditional Training Systems with Those of Our Training Model

\begin{tabular}{|c|c|}
\hline Surgical Training Tool & $\begin{array}{c}\text { Approximate } \\
\text { Cost (U.S. Dollars) }\end{array}$ \\
\hline 1. Training surgical microscope & $5000-10,000$ \\
\hline $\begin{array}{l}\text { 2. Endoscope set (0- and } 30 \text {-degree scopes), } \\
\text { endoscope camera and monitor }\end{array}$ & $35,000-60,000$ \\
\hline 3. Exoscope & $4000-10,000$ \\
\hline \multicolumn{2}{|l|}{ 4. Our training system*: } \\
\hline $\begin{array}{l}\text { Mac computer } \\
\text { iPhone } 6 \\
\text { VR glasses } \\
\text { Total cost }\end{array}$ & $\begin{array}{l}=1000-1500 \\
=350-400(\times 2) \\
=40 \\
=1740-2340\end{array}$ \\
\hline \multicolumn{2}{|c|}{$\begin{array}{l}\text { *We used Mac computers and iPhones due to their availability in our department. } \\
\text { However, other personal computers and smartphones could be easily adapted and } \\
\text { effectively used for our training system. }\end{array}$} \\
\hline
\end{tabular}

\section{DISCUSSION}

It is undeniable the importance that the surgical microscope, with its high illumination and $3 \mathrm{D}$ magnification, has had on the development of modern neurosurgery over the past 50 years. Still nowadays, the majority of the most complex neurosurgical procedures are performed using an operating microscope. ${ }^{\mathrm{I}-3,6-8}$

However, in the past decades endoscopes and exoscopes have been increasingly used in neurosurgery as they may offer a valuable close-up view of the working area through a minimally invasive surgical corridor. ${ }^{4,5}$

If the microscope offers a straight view of the surgical field, endoscopes and exoscopes require an "EHB technique."

As demonstrated by some authors, a smartphone could represent an excellent tool for microsurgical training. ${ }^{- \text {-II }}$ However, long time periods of training using the small screen of a smartphone may be tiring.

Hence we connected the smartphones to a personal computer screen and/or to VR glasses in order to improve and make more comfortable the training sessions. Our training model allowed us to exercise our eye-hand coordination and dexterity in microsurgical procedures without the need of expensive surgical devices (microscope, endoscope, or exoscope), which are not always available for neurosurgical residents or young neurosurgeons.

Our training system is based on "technologic tools" that are already mostly owned by any trainee (iPhones or other smartphones, personal computers). We used Mac computers and iPhones due to their availability in our department. However, other personal computers and smartphones could be easily adapted and effectively used for our training system. Nowadays, most of the students and professionals use a personal computer 


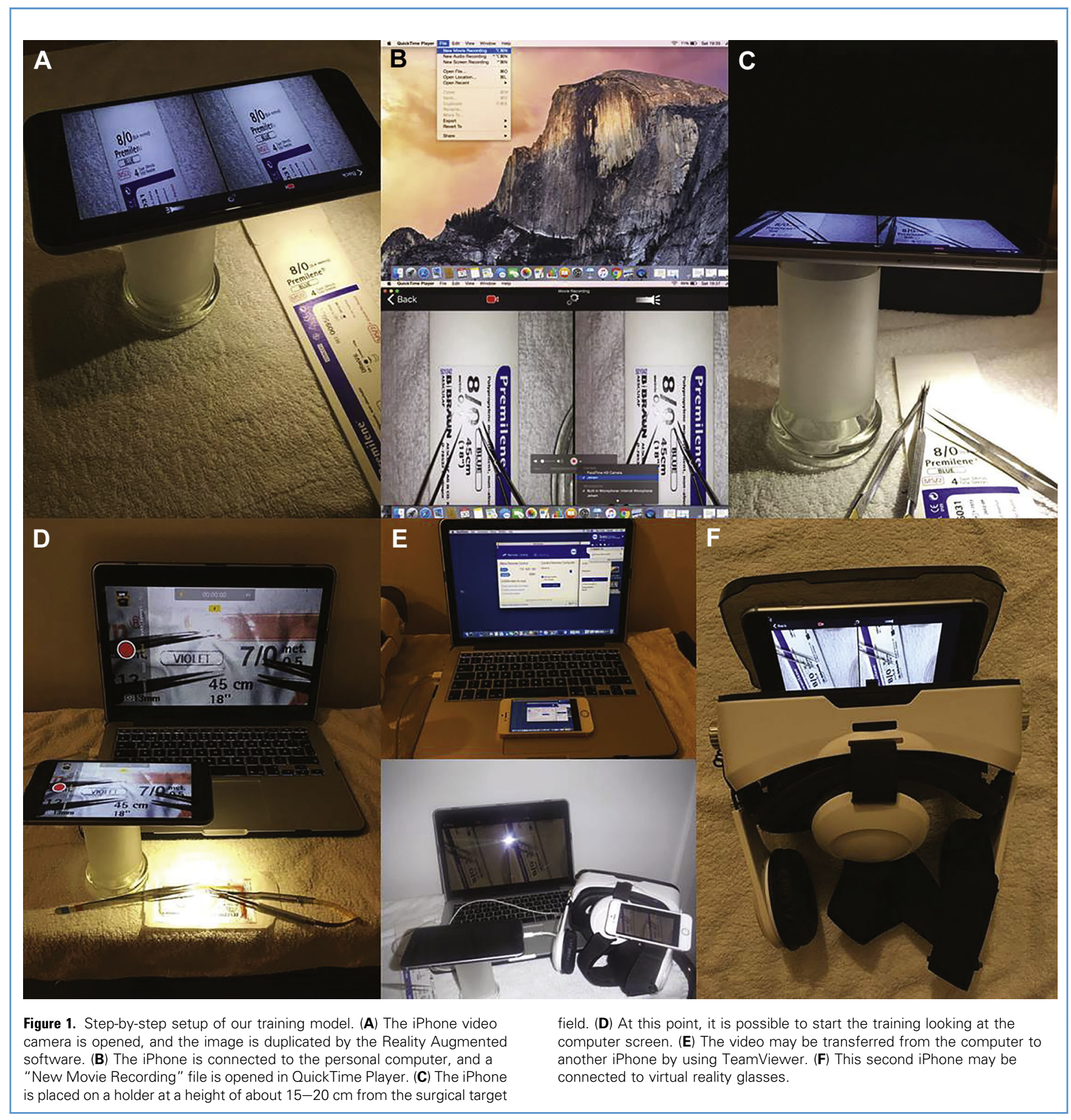

and/or a smartphone for their daily activities. As a consequence, our training model is designed for any medical student, resident, fellow, or surgeon with almost no-extra cost. Moreover, our system may be easily transported and used for surgical training in any available place.

A limitation of the proposed training system is represented by the difficulty to define a tridimensional space in the computer screen. However, continuous training could help in this regard. Moreover, a 3 -dimensional video maker software together with ${ }_{3} \mathrm{D}$ glasses could easily solve the problem. Currently, programs such as Adobe Premier Pro can produce a red cyan 3-dimensional video. On the other hand, nearly future smartphones such as the iPhone 8 -iPhone $\mathrm{X}$ would solve this issue using their cameras in portrait mode. 


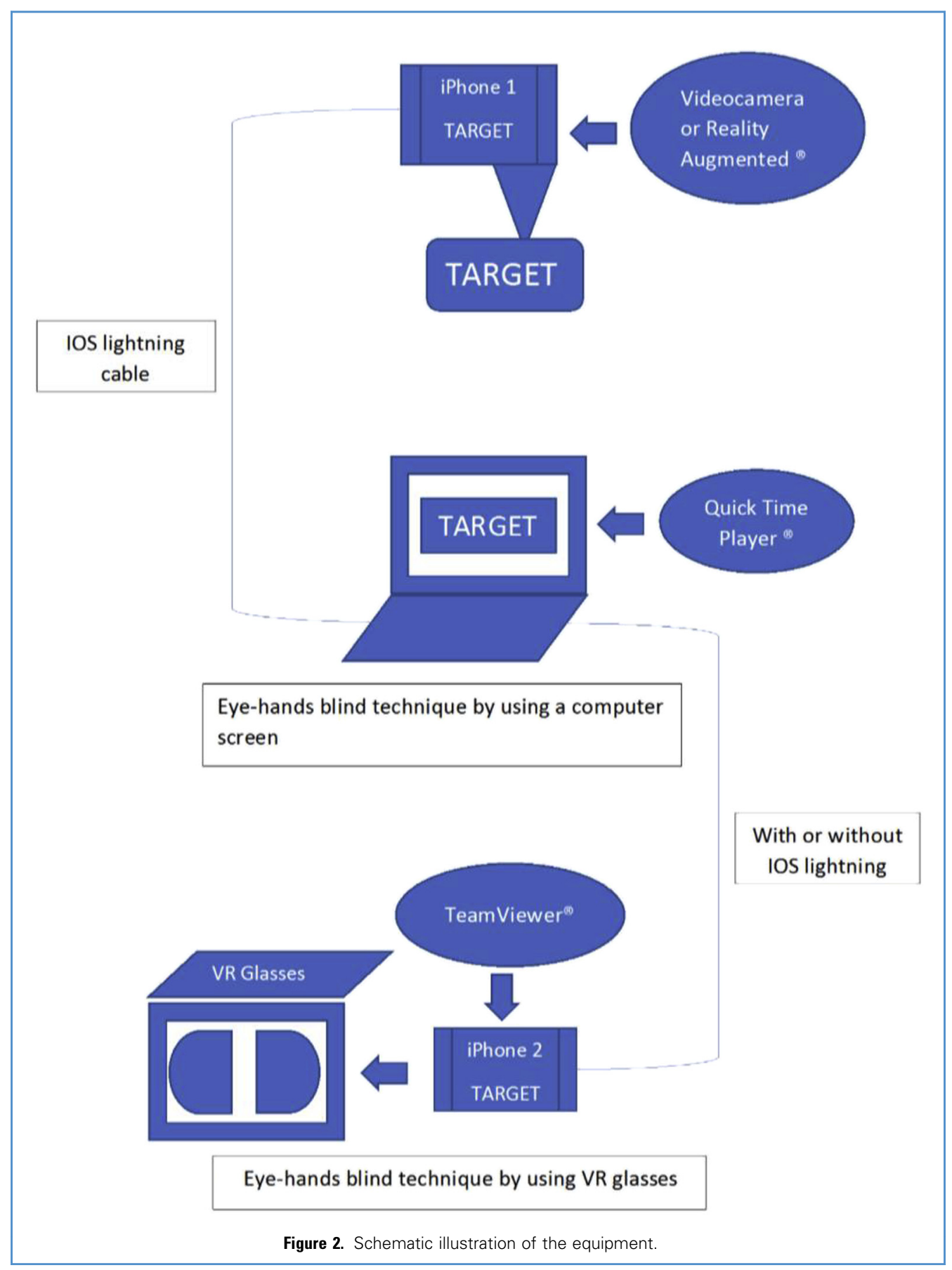

Regarding the VR glasses, even though we were able to perform some demanding microsutures, those still have some limitations in offering high-resolution images. However, we believe that the future generation of these devices will overcome these problems.

\section{CONCLUSION}

In conclusion, our proposed training model may represent an affordable and efficient system to improve eye-hand coordination and dexterity in using not only the operating microscope but also endoscopes and exoscopes. 
Table 2. Analysis of Recorded Training Sessions of Neurosurgeon with 3 Years of Experience

\begin{tabular}{|c|c|c|c|c|}
\hline $\begin{array}{l}\text { Time to Perform } \\
5 \text { Consecutive } \\
\text { Sutures (Seconds) }\end{array}$ & $\begin{array}{l}\text { Computer } \\
\text { Screen } \\
\text { (7-0 Suture) }\end{array}$ & $\begin{array}{c}P \text { Value } \\
\text { (2-tailed Student's } \\
t \text {-test) }\end{array}$ & $\begin{array}{c}\text { Virtual Reality } \\
\text { Glasses } \\
\text { (7-0 suture) }\end{array}$ & $\begin{array}{c}P \text { Value } \\
\text { (2-tailed Student's } \\
t \text {-test) }\end{array}$ \\
\hline Initial baseline training set & $594.47 \pm 65.84$ & & $1157.75 \pm 71.77$ & \\
\hline 3-months' training sessions & $443.9 \pm 33.73$ & $<0.001$ & $584.28 \pm 33.79$ & $<0.001$ \\
\hline 5-months' training sessions & $317.33 \pm 23.82$ & $<0.001$ & $321.21 \pm 31.89$ & $<0.001$ \\
\hline
\end{tabular}

\section{REFERENCES}

I. Krayenbühl H, Yasargil MG. [The use of binocular microscopes in neurosurgery]. Wien Z Nervenheilkd Grenzgeb. I967;25:268-277.

2. Yaşargil MG, Krayenbühl H. The use of the binocular microscope in neurosurgery. Bibl Ophthalmol Suppl Ad Ophthalmol. 1970;8r:62-65.

3. Jannetta PJ. The surgical binocular microscope in neurological surgery. Am Surg. I968;34:3I-34.

4. Griffith HB. Technique of fontanelle and persutural ventriculoscopy and endoscopic ventricular surgery in infants. Childs Brain. I975; $1: 359-363$.

5. Gildenberg PL, Ledoux R, Cosman E, Labuz J. The exoscope-a frame-based video/graphics system for intraoperative guidance of surgical resection. Stereotact Funct Neurosurg. 1994;63:23-25.

6. Rand RW, Jannetta PJ. Microneurosurgery: application of the binocular surgical microscope in brain tumors, intracranial aneurysms, spinal cord disease, and nerve reconstruction. Clin Neurosurg. I968;15:319-342.

7. Velasquez JC, Lau J, Kozyrev D, Sharafeddin F, Colasanti R, Luostarinen T, et al. Clean, fast and preserving normal anatomy: "the Helsinki revolution" in microneurosurgery. J Neurosurg Sci. 2016; 6o: $44-53$.

8. Choque-Velasquez J, Kozyrev DA, Colasanti R, Thiarawat P, Intarakhao P, Jahromi BR, et al. The open access video collection project "Hernesniemi's roor and More Microsurgical Videos of Neurosurgery": a legacy for educational purposes. Surg Neurol Int. 2017;8:188.

9. Huotarinen A, Niemelä M, Jahromi BR. Easy, efficient and mobile way to train microsurgical skills during busy life of neurosurgical residency in resource-challenged environment. World Neurosurg. 2017;107:358-36r.
Io. Kim DM, Kang JW, Kim JK, Youn I, Park JW. Microsurgery training using a smartphone. Microsurgery. 2015;35:500-50I.

II. Karakawa R, Yoshimatsu H, Nakatsukasa S, Iida T. A new method for microsurgery training using a smartphone and a laptop computer. Microsurgery. 20I8;38:I24-I25.

Conflict of interest statement: The authors have no personal financial or institutional interest in any of the drugs, materials, and devices described in this article.

Received 13 October 2017; accepted 11 January 2018

Citation: World Neurosurg. (2018) 112:126-130. https://doi.org/10.1016/j.wneu.2018.01.067

Journal homepage: www.WORLDNEUROSURGERY.org Available online: www.sciencedirect.com 1878-8750/\$ - see front matter (C) 2018 Elsevier Inc. All rights reserved. 